\title{
One of Two Conductors in Capacitor Substitute by Mercury
}

\author{
Mohammad Mehdi Masoumi and Soheila Naderinezhad
}

\begin{abstract}
Each capacitor generally consists of two conductors separated by a non-conductive region, however a great changed happened in the modern capacitors but the principle has been remained the same as the first day designed. In this paper was attempted to show novel capacitor which one of the conductors was coated and covered with dielectric and sunk into another conductive liquid which supposed as conductor and it is mercury because of two important features, the first being conductive and second the liquidity. In this paper experimented by the lacquer coated wire and the aluminum plate submerged into mercury then in experiments mercury charged and discharged, as a result it was working as a capacitor. The experiments was done by following sets: a DC power supply (DF1730 SB5A), multimeter, an LC meter (A6243- HONEYTEK).the experiment results showed that mercury could appropriately substitute by one of two conductors in capacitors. In addition, the simulation will have higher capacity till one farad and more.
\end{abstract}

Keywords--- Mercury, Capacitor, Mercury Capacitor, Increase Capacity Of Capacitor, High Farad Modeling Via Mercury

\section{INTRODUCTION}

$\mathrm{T}$ HE beginning of capacitor technology is generally attributed to the invention in October 1745 of the Leyden jar by the German Ewald Georg von Kleist. Independently, Pieter van Musschenbroek, a Dutch physicist at the University of Leyden, discovered the Leyden jar in 1746 [1]. A waximpregnated paper dielectric capacitor with foil electrodes was invented by Fitzgerald in 1876 [2]. Mica dielectric capacitors were invented in 1909 by William Dubilier. Capacitor technology did not evolve rapidly until the invention of the vacuum tube, which facilitated electronic amplifiers required for long-distance telephone (coast-to-coast, 1915) and practical radio technology first licensed commercially in 1920; however, the first AC line powered radio was not introduced until 1927 (RCA Radiola 17) [3]. In 1936, Cornell-Dubilier opened a factory in Plainfield, NJ, and introduced a line of commercial Al electrolytic capacitors and Electrolytic capacitors did not become highly reliable until World War II [6]. Ceramics have been used as electrical insulation since the

Mohammad Mehdi Masoumi, Department of Civil Engineering, Engineering Faculty, Young Researchers and elite Club of Islamic Azad University, Science and Research Branch, Fars, Iran, Email:m.masoumi@rocketmail.com

Soheila Naderinezhad,, Department of Electrical Engineering, Islamic Azad University, Science and Research Branch, Fars, Iran. E-mail: soheila.naderinezhad@gmail.com earliest studies of electricity. As noted earlier, the first capacitor, the Leyden jar, was a ceramic capacitor. Prior to World War II, mica was the most common ceramic dielectric for capacitors, although porcelain, steatite, cordierite, and rutile were also used. Capacitors based on titanium dioxide (rutile) were avail-able commercially around 1926. The 1941 discovery of barium titanate with a dielectric constant in the range of 1,000 , about 10 times greater than any dielectrics known at the time [5]. In the following decades, a great deal of effort was devoted to understanding the crystallography, phase transitions, and the optimization of this family of materials [5]. The development of multilayer ceramic capacitor fabrication using the tape casting and ceramic electrode cofiring processes during the 1970s and 1980s expanded the range of ceramic capacitor Application to larger capacitances and higher voltages depending on whether the layers were arranged in series or parallel [3].The lacquer reduced electrolytic corrosion of the metal and increased insulation resistance. Further attention was given to metalized paper capacitors around 1950 when they were in 1950 s and was produced as $12-\mu \mathrm{m}$ metalized capacitor film by1954 [6].Capacitors based on electric double-layer charge storage were first patented by General Electric in 1957 but were never commercialized. Subsequent double-layer capacitor designs patented by Standard Oil of Ohio did lead to commercial product introduction in 1978 by Nippon Electric Corporation. Their Super capacitor trademarked product was rated at $5.5 \mathrm{~V}$ and had capacitance values up to $1 \mathrm{~F}$. These $5-\mathrm{cm} 3$ size or smaller capacitors were used as a battery, today, range in sizes up to 9 $\mathrm{kF}(9,000 \mathrm{~F})$ at $2.7 \mathrm{~V}$, with this largest-size device being easily held in one hand [3]. early Capacitors are known as condensers and they are still have occasional use, first time used for this purpose by Alessandro Volta [9] (who invited battery [10]) which can store more density of electrical charge than a conventional isolated conductor [9] while modern unit of capacitance was the jar, equal to approximately 1 nanofarad [11] which used by the Royal Navy [12]. And historical evidence showed that Mercury was used in ancient Egypt $1500 \mathrm{BC}$ [13] and in early China assigned as symbols of some beliefs such as prolonged life [14] and it is an electrically conductive liquid, it was used in mercury switches and so forth [15].

In this research it has been attempted discussion and introduced a new kind of capacitor which works such as other types especially to two layer capacitors. In contrast one of two layers is electrically conductive liquid that is mercury. This capacitor was worked by mercury. In the most two layers capacitor between layers there is a dielectric (figure 1-a) such as mercury capacitor. In mercury capacitor, the dielectric was surrounded around one layer and a second layer that is mercury surrounded the dielectric, so the dielectric and mercury were surrounded one layer (figure 1-b). 


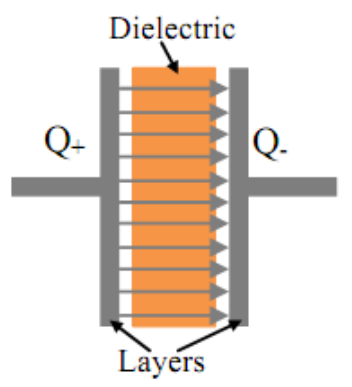

a

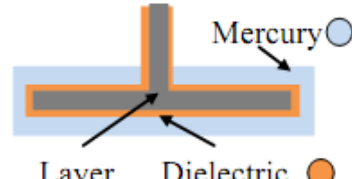

b

Fig.1 - Two layers capacitors (a) and schematic of the mercury capacitor (b)

\section{A. Experimental and modeling:}

A simple mercury capacitor was built from a mercury, a test tube with $1.8 \mathrm{~cm}$ interior diameter, a lacquer copper wire with $50 \mathrm{~cm}$ length and $0.5 \mathrm{~mm}$ diameter, in another experiment an aluminum foil coated with lacquer, and the experimental sets were a DC power supply (DF1730 SB5A), multimeter, an LC meter (A6243- HONEYTEK).

In a first experiment a model was contained the lacquer copper wire, the test tube and mercury. The lacquer copper wire changed to the spiral shape (like an armature winder) then was placed into the test tube when $2 \mathrm{ml}$ mercury added to it. The power supply approximately transferred 6.5 volts into mercury and the spiral copper wire due to charge the capacitor (figure 2-a). In next step was related to the shortcut between two conductive metal layers, that in mercury capacitor the layers were assumed as mercury and the copper wire. For checking the shortcut multimeter used, one side of the multimeter cable was connected to the spiral copper wire and other side was connected into mercury by using a conductive wire which inserted into mercury then measured the voltage potential between two parts. If the voltage potential did not equal to zero, ensure that they were isolated completely. The lacquer on the copper wire was bounded between parts which acted as dielectric. Then the multimeter replaced with the LC meter (figure 2-b) which measurement range has approximately been 2000pf to 200nf and also VC $6243-$ NICTOR that measurement range has approximately been $2 \mathrm{nf}$ to 1000 uf. The $\mathrm{LC}$ meter reference capacity (C reference) was assumed 20nf, the LC meter showed the capacity about $\mathrm{C}=$ $0.21 \mathrm{nf}$, it meant that the experimental model could charge electrical load. As the copper wire has lower density than mercury, the copper wire was forced to sinking into mercury which $16.5 \mathrm{~cm}$ the wire length was out of mercury. Capacity of capacitor increased when the amount of mercury was increased step by step till filled the spiral copper wire completely.

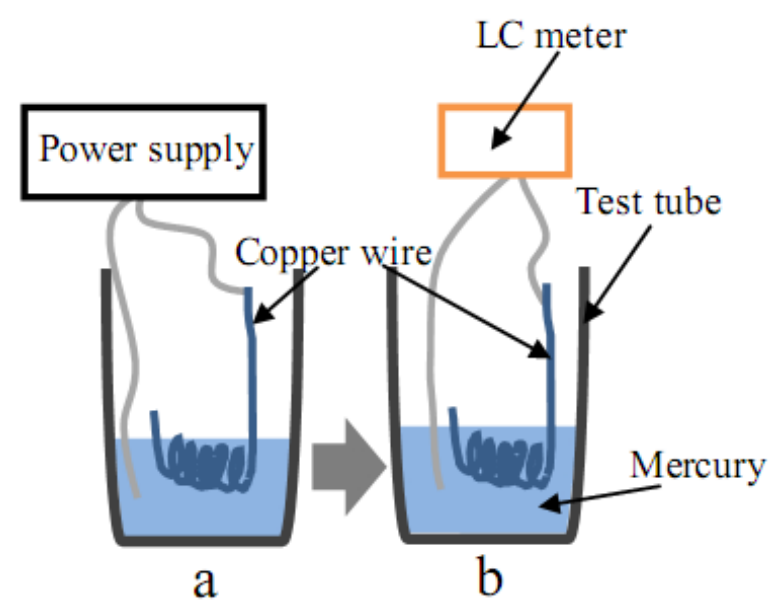

Fig.2- first experimental process [6]

In a second experiment the aluminum foil coated with lacquer then made two parallel layers which distance between layers approximately were $3 \mathrm{~mm}$ that like cube with $7 \mathrm{~cm} \mathrm{x} 4$ $\mathrm{cm}$ x $0.3 \mathrm{~cm}$ dimensions. The cube's edges were closed except one span opened with $4 \mathrm{~cm} \times 0.3 \mathrm{~cm}$ dimensions due to insert mercury. Inside the cube was coated with lacquer again in order to preventing shortcut. Then in a first step $2 \mathrm{ml}$ of mercury inserted into the coated foil caused bending and the distance between the layers a little exceeded more than $3 \mathrm{~mm}$ afterwards was tried to keeping initial distance manually. The shortcut checked such as the first experiment. A conductive wire was putted in mercury and connected to the one side of power supply and other side of the power supply was connected to the outside of the cube body where there was not lacquer that did not be interfering in the process of charging. Afterwards volume of mercury increased in each steps and capacities of capacitor in each steps were measured while volume of the aluminum cube was $8.4 \mathrm{~cm} 3$ and the maximum mercury volume was injected, was $7 \mathrm{~cm} 3$ which data showed in the table 1. In the experiment, errors influence on results such as manual controlled via hands which had vibration and influence on capacity and low precision of sets. The power supply transferred voltage approximately equaled $8 \mathrm{v}$. The LC meter used for checking the capacity which replaced with power supply .In this case in the first step the reference capacity (C reference) was assumed 20uf, the LC meter showed a capacity about $\mathrm{C}=0.23 \mathrm{uf}$.(Fig.3) 


\begin{tabular}{|c|c|}
\hline $\begin{array}{c}\text { Mercury Volume } \\
(\mathbf{m l})\end{array}$ & $\begin{array}{c}\text { Capacity } \\
\text { (uf) }\end{array}$ \\
\hline $\mathbf{2}$ & 0.23 \\
\hline $\mathbf{3}$ & $0.305-0.31$ \\
\hline $\mathbf{4}$ & $0.39-0.40$ \\
\hline $\mathbf{5}$ & 0.53 \\
\hline $\mathbf{6}$ & 0.63 \\
\hline $\mathbf{7}$ & $0.75-0.765$ \\
\hline
\end{tabular}

Tab.1 - experimental results of the Aluminum cube

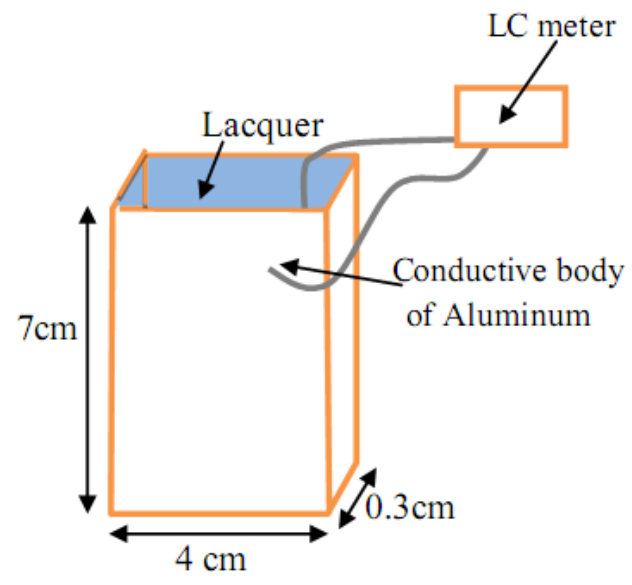

Fig.3- Aluminum cube model- Inside it filled with the mercury approximately increase till double first capacity, which equal 0.46 uf hence with increase plates increase the capacity. As mercury atomic radius is less than $160 \mathrm{pm}$ and the nano scales of perpendicular plates sink into mercury cause higher capacity. In these nano simulations are expected to increase capacity of capacitors till one farad or more. The schematic model of the nano simulation was shown in the figure 4 that the section a-a show the simulation before placing into mercury and section b-b showed after mercury added.

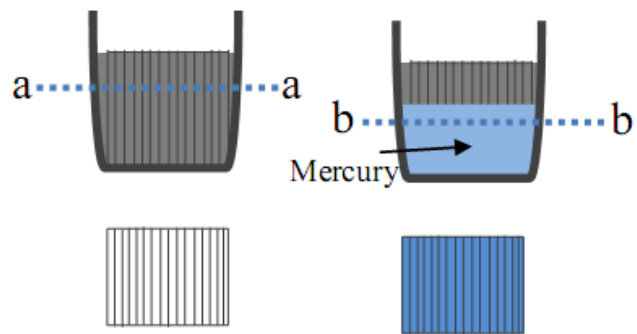

Fig.4- Schematic model of simulation

\section{Conclusion}

In this paper was attempted to show a new model of the capacitor which one of the conductors was coated and covered with none-conductive materials due to worked as dielectric and sunk into another conductive liquid which supposed as one of two conductors and it was assumed mercury because of two important features, the first being conductive and second the liquidity. In this paper experimented by the lacquer covered wire and the coated aluminum plate submerged into mercury then in experiments mercury charged and discharged, as a result it was working as a capacitor. The experiment results showed that mercury could appropriately substitute by one of two conductors in capacitors. In addition, the simulation will have higher capacity till one farad and more.

\section{ACKNOWLEDGMENT}

In the experimental of paper we highly appreciated from Mr. Jafar Fotovat for all his help.

\section{REFERENCES}

[1] Dummer G. W. A., Electronic Inventions and Discoveries, 4th ed. Bristol, UK: Institute of Physics Publishing, Pp. 74, 1997

[2] Fitzgerald D. G., Improvements in electrical condensers or accumulators, British Patent No. 3466/1876. 1876

[3] Ho J. and T. R. Jow, S. Boggs, 2010, Historical Introduction to Capacitor Technology, Feature Article DIES, IEEE Electrical Insulation Magazine, Vol. 26, No. 1 0883-7554/07, Available from: http://ieeexplore.ieee.org/xpl/articleDetails .jsp?tp=\&arnumber $=5383924 \&$ content Type $=$ Journals $+\% 26+$ Magazines \&queryText\%3DHistorical+Introduction+to+Capacitor (assessed on March 2012)

[4] IEEE global history network, Capacitors, assessed on http://www.ieeghn.org/wiki/index.php/Capacitors (May 2012)

[5] Mansbridge G. F., "The manufacture of electrical condensers," J. IEE, vol. 41, Pp. 535. 1908Available from: http://ieeexplore.ieee.org/xpl/articleDetails.jsp?tp=\&arnumber=5310280 
$\&$ contentType $=$ Journals $+\% 26+$ Magazines\&queryText $\% 3$ DThe + manufa cture+of+electrical+condensers (Assessed on April 2012)

[6] Masoumi M., Habibi Ardekani F "Seismometer Working with Mercury", Open Access Scientific Reports, Volume 1 Issue 11,2012

[7] McLean D. A. and H.G. Wehe, "Miniature lacquer film capacitors," Proc. IRE, vol. 42, no. 12, Pp. 1799-1805. 1954

[8] Niwa S. and Y. Taketani, , "Development of new series of aluminums solid capacitors with organic semi conductive electrolyte (OS-CON)," J. Power Sources, vol. 60, pp. 165-171. 1996

[9] Appleton D., "Sketch of Alessandro Volta". The Popular Science Monthly, New York Publisher, Pp.118-119. 1892. ISSN 0161-7370

[10] Allen J. Bard, György Inzelt, Fritz Scholz " Electrochemical Dictionary ", Springer Press, Pp. 955-956, 2008

[11] "eFunda: Glossary: Units: Electric Capacitance: Jar". eFunda, access on 12. http://www.efunda.com/glossary/units/units--electric_capacitance-jar.cfm (Retrieved 2013)

[12] Admiralty Handbook of Wireless Telegraphy, Majesty's Stationary Office, HMSO, London. p.119, 1932,

[13] "Mercury and the environment - Basic facts". Environment Canada, Federal Government of Canada access on http://www.ec.gc.ca/mercuremercury/default.asp?lang=En\&n=9A4397AD-1 (Retrieved 2008)

[14] "Mercury - Element of the ancients". Center for Environmental Health Sciences, Dartmouth College. Access http://www.dartmouth.edu/ toxmetal/mercury/history.html (2012)

[15] Shelton, C, Electrical Installations. Nelson Thornes. p. 260. (2004). 